\title{
AN ALTERNATIVE DELIVERY DEVICE IN NASAL IRRIGATION AFTER SINUS SURGERY
}

\author{
Nagendran Navaneethan'1, Praveen Kumar Jayaraj², Udaya Kumar Muthu Kumar³, Ramanathan Thirunavukkarasu4
}

${ }^{1}$ Associate Professor, Department of ENT, Melmaruvathur Adhiparasakthi Institute of Medical Sciences and Research, Melmaruvathur. ${ }^{2}$ Assistant Professor, Department of ENT, Melmaruvathur Adhiparasakthi Institute of Medical Sciences and Research, Melmaruvathur. ${ }^{3}$ Assistant Professor, Department of ENT, Melmaruvathur Adhiparasakthi Institute of Medical Sciences and Research, Melmaruvathur. ${ }^{4}$ Professor and HOD, Department of ENT, Melmaruvathur Adhiparasakthi Institute of Medical Sciences and Research, Melmaruvathur.

ABSTRACT

\section{BACKGROUND}

Paranasal sinus problems are one among the major identified ENT symptoms in outpatients. Whenever there are alterations in nasal secretions and hindrance in drainage of sinuses, sinus diseases arise. To clear and maintain the proper sinus clearance, alkaline douche, a technique which is already proven and instantly made can be used. This research work tries to evaluate the feasibility of using $20 \mathrm{~mL}$ disposable syringe as a nasal delivery device in place of the routine red rubber bulb (RBB) in postoperative sinus patients.

\section{MATERIALS AND METHODS}

One hundred and twenty patients who underwent functional endoscopic sinus surgeries during the tenure of 2013 to 2015 in Melmaruvathur Adhiparasakthi Institute of Medical Sciences and Research (MAPIMS) were followed up postoperatively. Simple random sampling was done and was divided into two groups. One group used red rubber bulb and the other group used plastic syringe as a nasal delivery device. All patients were enquired with preformed questionnaires regarding pain and compliance and diagnostic endoscopic findings pertaining to persistent nasal discharge and synechiae were documented.

\section{RESULTS}

Syringe users showed lesser compliance than RRB users. It was evident that plastic material was more irritant than rubber bulb which was found out through questionnaire. Synechiae formation is more common in plastic syringe (39\%) compared to RRB users $(22 \%)$ especially in the region of anterior end of inferior turbinate, but these results doesn't satisfy the statistical significance $(\mathrm{p}=1.22)$.

\section{CONCLUSION}

Even though disposable syringe is easily and readily available delivery device, its lesser compliance, more synechiae formation limits recommendation of plastic syringe to our post-operative patients.

\section{KEYWORDS}

Plastic Syringe, Red Rubber Bulb, Nasal Delivery Device.

HOW TO CITE THIS ARTICLE: Navaneethan N, Jayaraj PK, Kumar UKM, et al. An alternative delivery device in nasal irrigation after sinus surgery. J. Evolution Med. Dent. Sci. 2017;6(19):1498-1500, DOI: 10.14260/Jemds/2017/328

\section{BACKGROUND}

Paranasal sinuses are a group of air containing spaces around the nasal cavity. Mucosal secretion and air conditioning are primary functions of sinuses which is maintained properly by the mucociliary clearance of cilia present in the sinus. Any dysfunction in clearance leads to stasis of mucosal secretion and subsequently causes acute inflammation of the sinuses. The motto of the surgery is to widen the outflow tracts of sinuses.

Functional endoscopic sinus surgery helps to improve sinus ventilation and retain mucociliary clearance. The goal is to maintain the patency and mucociliary clearance after surgery. Nasal douching is one such manoeuvre to fulfil the

Financial or Other, Competing Interest: None.

Submission 10-01-2017, Peer Review 19-02-2017,

Acceptance 25-02-2017, Published 06-03-2017.

Corresponding Author:

Nagendran Nananeethan,

Associate Professor

Department of ENT

Melmaruvathur Adhiparasakthi Institute of

Medical Sciences, Melmaruvathur.

E-mail: naugendran888@gmail.com

DOI: $10.14260 /$ jemds $/ 2017 / 328$

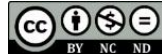

requirement. Here, the challenge lies in selecting the ideal solution and ideal delivery device. Isotonic saline solution, hypertonic saline, ${ }^{1}$ sea water ${ }^{2}$ and baby shampoo ${ }^{3}$ were tried in various studies. Otolaryngologists observed that saline irrigation after surgery reduced the risk of postoperative mucosal adhesions and enhanced mucosal healing rather than just clearing secretions, debris and crusts. ${ }^{4}$ Universally accepted ideal recipe for douching is salt and sodium bicarbonate in water.

The ideal delivery system should be comfortable to use, easy to clean, and inexpensive. Two varieties of device already exist in the market namely "Negative pressure delivery device" and "Positive pressure delivery device". Solution being drawn into the nose, i.e. sniffed from a bottle or snorted from a cupped hand is called negative pressure delivery. Positive pressure devices actively deliver the solution into the nose, either by gravity (neti pot), handgenerated pressure (bulb syringe, squeeze bottle).

Red rubber bulb syringe is the preferred delivery device in many hospitals all over the world. It satisfies two criteria i.e. comfortable to use and inexpensive but difficult to clean. Cleaning and sterilisation can be done by placing in hot water, which subsequently leads to spoilage of rubber. In case of replacement especially for patients residing in rural areas, he/she needs to commute to nearby hospitals to avail or buy 
the red rubber bulb. This ultimately leads to discontinuation of nasal douching.

To solve this problem, this paper discusses on an alternative delivery device which uses $20 \mathrm{~mL}$ disposable plastic syringe which is comfortable to use, inexpensive and also readily available in all pharmacies. This study had a valid reason of selecting $20 \mathrm{~mL}$ syringe because of easy availability which makes it replaceable without difficulty instead of repeated sterilisation.

\section{MATERIALS AND METHODS}

Around 120 functional endoscopic sinus surgeries with or without septoplasty for sinusitis and sinonasal polyposis in MAPIMS were carried out between the years 2013-2015. Importance was given to post-operative nasal cleaning to maintain sinus drainage naturally. The routine alkaline douche recipe was not changed, whereas alternative nasal delivery device (i.e.) $20 \mathrm{~mL}$ disposable plastic syringe was used instead of routine red rubber bulb. The study group was divided in to two groups by simple random sampling.

The inclusion criteria incorporated the following - (a) Age above 22 years, (b) Endoscopic sinus surgery patients for sinusitis and sinonasal polyposis, (c) Patient's acceptance and consent for study.

The exclusion criteria had the following - (a) Patients who doesn't turn up for regular review (at least once in a month for six months or totally 6 visits in 6 months), (b) Patients who haven't used nasal douching method.

Alkaline douche solution is prepared by adding 2 tablespoons of common salt and 1 tablespoon of baking powder in one litre of lukewarm water. Patients were advised to use half litre of solution three times daily. Douche solution is sucked into the nasal delivery device (red rubber bulb and $20 \mathrm{~mL}$ plastic syringe) and the crusts in the post-operative nasal cavity were flushed out by inserting tip of the device in to anterior naris. Patients were cautioned that initial use of nasal douching may cause tickling sensation of the nose and sometimes mild spot bleeding can be noticed in the discharged douche solution.

\section{RESULTS}

The findings were made in 120 patients, out of which only 88 of them had satisfied both inclusion and exclusion criteria. 47 were male $(53.4 \%)$ and 41 were female $(46.6 \%)$ in the above mentioned 88, in which 32 of them used red rubber bulb and 56 people used plastic syringe. Each of them had regular followup.

\begin{tabular}{|c|c|c|}
\hline & Frequency & Percent \\
\hline Female & 41 & 46.6 \\
\hline Male & 47 & 53.4 \\
\hline Total & $\mathbf{8 8}$ & $\mathbf{1 0 0 . 0}$ \\
\hline \multicolumn{3}{|c|}{ Table 1. Sex Distribution } \\
\hline
\end{tabular}

Criteria was fixed to achieve good compliance wherein the patients were advised to use delivery devices at least once in a day, even if they had issues like nasal pain, lack of time, etc. Red rubber users showed good compliance than syringe users. As per the questionnaire it was clear that the patients preferred rubber material than the plastic syringe because of its less irritancy. Our results also satisfied statistical significance.

\begin{tabular}{|c|c|c|c|}
\hline & Good & Poor & Total \\
\hline Red Rubber & 25 & 7 & 32 \\
\hline$\%$ & $78 \%$ & $22 \%$ & $36 \%$ \\
\hline Syringe & 31 & 25 & 56 \\
\hline$\%$ & $55 \%$ & $45 \%$ & $64 \%$ \\
\hline Total & $\mathbf{5 6}$ & $\mathbf{3 2}$ & $\mathbf{8 8}$ \\
\hline$\%$ & $64 \%$ & $36 \%$ & \\
\hline \multicolumn{4}{|c|}{ Table 2. Compliance of Nasal Douching } \\
\hline
\end{tabular}

Fifty four percent of syringe users experienced pain during nasal douching compared to thirty one percent RRB users. The pressure exerted in the plastic syringe is along the direction of water flow; syringe moves and hits the nasal mucosa while pressing the piston. This was found to be a reason for more pain in patients using syringe.

\begin{tabular}{|c|c|c|c|}
\hline & \multicolumn{3}{|c|}{ Pain } \\
\hline & No & Yes & Total \\
\hline Red rubber & 22 & 10 & 32 \\
\hline$\%$ & $69 \%$ & $31 \%$ & $36 \%$ \\
\hline Syringe & 26 & 30 & 56 \\
\hline$\%$ & $46 \%$ & $54 \%$ & $64 \%$ \\
\hline Total & 48 & 40 & 88 \\
\hline$\%$ & $55 \%$ & $45 \%$ & \\
\hline & Chi Square & $4.09 *$ & $\mathrm{P}<0.05$ \\
\hline
\end{tabular}

The most common undesirable presentations of the study were pain and synechiae formation. The extent of study of using these two techniques is limited by the above mentioned presentations. Based on the post-operative evaluation of the usage of RRB \& $20 \mathrm{~mL}$ syringe and also considering the limiting factors, it is found out that synechiae formation is the most common complication of both techniques. Its incidence is lesser in RRB users. The study also aimed at an important outcome in post FESS patients which was judged by the persistence of nasal discharge in the corresponding sinus surgery area, during diagnostic nasal endoscopy. Plastic syringe users had little more percentage of nasal discharge than that of rubber bulb users as shown in the Table 4.

\begin{tabular}{|c|c|c|c|c|c|c|}
\hline \multicolumn{7}{|c|}{ Cross Tabulation } \\
\hline & & & \multicolumn{3}{|c|}{ Endoscopic Findings } & \multirow{3}{*}{\begin{tabular}{|c|} 
Total \\
32
\end{tabular}} \\
\hline & & & Discharge & Normal & Synechiae & \\
\hline \multirow{4}{*}{$\begin{array}{c}\text { Treat- } \\
\text { ment }\end{array}$} & \multirow{2}{*}{$\begin{array}{c}\text { Red } \\
\text { Rubber }\end{array}$} & Count & 6 & 19 & \begin{tabular}{|l|}
7 \\
\end{tabular} & \\
\hline & & $\%$ & $19 \%$ & $59 \%$ & $22 \%$ & $36.4 \%$ \\
\hline & \multirow{2}{*}{ Syringe } & Count & 13 & 21 & 22 & 56 \\
\hline & & $\%$ & $23 \%$ & $38 \%$ & $39 \%$ & $63.6 \%$ \\
\hline \multirow{2}{*}{\multicolumn{2}{|c|}{ Total }} & Count & 19 & 40 & 29 & 88 \\
\hline & & $\begin{array}{c}\% \\
\text { within } \\
\text { DNE }\end{array}$ & $100.0 \%$ & $100.0 \%$ & $100.0 \%$ & $\begin{array}{c}100.0 \\
\%\end{array}$ \\
\hline \multicolumn{7}{|c|}{ Table 4. Endoscopic Findings in Both Groups } \\
\hline
\end{tabular}

Chi square $=4.205, \mathrm{p}=0.122$ non-significant

\section{DISCUSSION}

Nasal douching with saline is the preferred solution ${ }^{5}$ in postFESS patients in many institutes all over the world. The only difference is in the way it is delivered like using neti pot, nasal spray, irrigation bottles, etc. In this study, $20 \mathrm{~mL}$ plastic syringe (nasal delivery device) was introduced with the regime of nasal irrigation, where the patient has to use it at least once a day. 
Wei JL et al ${ }^{6}$ tried once daily irrigation in his study, but they tried in unoperated paediatric patients with chronic rhinosinusitis and their duration of followup was six weeks only. Compliance in their study was about $94 \%$ which is greater than best compliance in red rubber users $(78 \%)$ in our study. Wei JL also documented high tolerance, compliance, and effectiveness of nasal irrigation made it as a first-line treatment for paediatric chronic rhinosinusitis even before considering surgical intervention.

Around $45 \%$ of plastic syringe users and $22 \%$ of red rubber bulb users in this study discontinued the douching. Mari Egan ${ }^{7}$ also documented significant portion (21\%) of pot users and $7 \%$ of nasal spray users discontinued treatment in his study. The reasons for non-compliance in this study were nasal pain, irritant plastic material, burning sensation due to saline solution, etc.

Out of 120 patients, only 88 (73.33\%) patients had regular followup which is comparatively greater than $51.4 \%$ patients in Keerl $\mathrm{R}^{5}$ et al study. But their followup period was greater for about 27-36 months compared to the followups that was carried out in our study postoperatively for a period of six months.

Rabago D quoted that acceptance, ease of use, training, cost, and head position may all contribute to the overall effectiveness of nasal delivery devices in nasal irrigation. ${ }^{8}$ Both Brook I and Heatley DG accepted that reusable products has lower cost per irrigation compared with preformed nasal sprays, although there may be more risk of contamination in reusable delivery products.9,10 The product in this study had low volume $(20 \mathrm{~mL})$ compared to rubber bulb which has a capacity to deliver $80 \mathrm{~mL}$ and also there is difference in the direction of pressure exertion. Even though the red rubber bulb is $2.5 \mathrm{~cm}$ long, it can reach the nasal cavity only up to 1 $\mathrm{cm}$ from the external naris which can be done with the plastic syringe itself. Synechiae was present more in the plastic syringe users (39\%) than rubber bulb users (22\%) especially in between inferior turbinate and nasal septum and approximately $1 \mathrm{~cm}$ from external naris. The direction of pressure exertion in syringe was parallel to the direction of water flow which made the syringe to move forward. This was the cause for more synechiae formation and its plastic consistency also caused more pain. The pressure exerted in the red rubber bulb was perpendicular to the direction of water flow and there was no forward movement of tip of rubber bulb during nasal cleaning, which caused comparatively lesser synechiae and its rubber material caused lesser pain.

\section{CONCLUSION}

The above article with detailed study took up plastic syringe as an alternative delivery device for nasal irrigation. Positive aspects of using this device are that the plastic syringes are easily available, easy to use, can be replaced easily, etc., Test and trials were made and the feasibility of using this device resulted only up to $55 \%$ because of its evident formation of synechiae and pain.

\section{REFERENCES}

[1] Hauptman G, Ryan MW. The effect of saline solutions on nasal patency and mucociliary clearance in rhinosinusitis patients. Otolaryngol Head Neck Surg 2007;137(5):815-21.

[2] Bonnomet A, Luczka E, Coraux C, et al. Non-diluted seawater enhances nasal ciliary beat frequency and wound repair speed compared to diluted seawater and normal saline. Int Forum Allergy Rhinol 2016;6(10):1062-8.

[3] Chiu AG, Palmer JN, Woodworth BA, et al. Baby shampoo nasal irrigations for the symptomatic postfunctional endoscopic sinus surgery patient. Am J Rhinol 2008;22(1):34-7.

[4] Tomooka LT, Murphy C, Davidson TM. Clinical study and literature review of nasal irrigation. Laryngoscope 2000;110(7):1189-93.

[5] Keerl R, Weber R, Müller C, et al. Effectiveness and tolerance of nasal irrigation following paranasal sinus surgery. Laryngorhinootologie 1997;76(3):137-41.

[6] Wei JL, Sykes KJ, Johnson P, et al. Safety and efficacy of once-daily nasal irrigation for the treatment of pediatric chronic rhinosinusitis. Laryngoscope 2011;121(9):1989-2000.

[7] Egan M, Hickner J. Saline irrigation spells relief for sinusitis sufferers. J Fam Pract 2009;58(1):29-32.

[8] Rabago D, Barrett B, Marchand L, et al. Qualitative aspects of nasal irrigation use by patients with chronic sinus disease in a multimethod study. Ann Fam Med 2006;4(4):295-301.

[9] Brook I. Bacterial contamination of saline nasal spray/drop solution in patients with respiratory tract infection. Am J Infect Control 2002;30(4):246 -7.

[10] Heatley DG, McConnell KE, Kille TL, et al. Nasal irrigation for the alleviation of sinonasal symptoms. Otolaryngol Head Neck Surg 2001;125(1):44-8. 